\title{
Acanthosis nigricans: To be or not to be afraid (Review)
}

\author{
MARIA-LINDA POPA ${ }^{1,2^{*}}$, ADRIAN CLAUDIU POPA $^{3 *}$, CRISTIANA TANASE $^{2}$ \\ and ANCUTA-AUGUSTINA GHEORGHISAN-GALATEANU ${ }^{1,4}$

\begin{abstract}
${ }^{1}$ Department of Cellular and Molecular Biology and Histology, 'Carol Davila' University of Medicine and Pathology, 050096 Bucharest; ${ }^{3}$ Army Centre for Medical Research, 010195 Bucharest;

${ }^{4}$ ‘C.I. Parhon’ National Institute of Endocrinology, 001863 Bucharest, Romania
\end{abstract} \\ Pharmacy, 050474 Bucharest; ${ }^{2}$ Department of Biochemistry-Proteomics, 'Victor Babes' National Institute of
}

Received July 3, 2018; Accepted August 14, 2018

DOI: $10.3892 / 01.2018 .9736$

\begin{abstract}
Acanthosis nigricans (AN), a skin disorder with high prevalence, represents a dermatological condition with esthetic implications, but otherwise mild symptoms. For any clinician, it is in fact the tip of the iceberg, leading him/her to investigate what lies beneath the surface, since AN points to a systemic problem or disease: metabolic disorder (most frequently), endocrine syndrome, medication side effects, malignancy, and genetic factors. Sometimes, it is the first observed sign of a malignancy or of diabetes mellitus, especially in patients with chronic metabolic disorder; therefore, it is not to be taken lightly. The present review summarizes the information in literature regarding the etiopathogenesis of AN. We propose a new classification that aims to better organize the different types of AN, with implications on the extent and urgency of the investigation plan, as well as various therapeutic algorithms. Therapy options are also presented, both systemic treatments that target the underlying disease, and local ones for esthetic reasons.
\end{abstract}

\section{Contents}

1. Introduction

2. Methods

3. Etiology

4. Diagnosis

5. Pathological conditions and disorders associated with acanthosis nigricans

6. Pathophysiology

Correspondence to: Professor Cristiana Tanase, Department of Biochemistry-Proteomics, 'Victor Babes' National Institute of Pathology, 99-101 Splaiul Independentei, 050096 Bucharest, Romania

E-mail: bioch@vbabes.ro

*Contributed equally

Key words: acanthosis nigricans, insulin resistance, endocrine disorders, paraneoplastic syndrome, hyperpigmentation, differential diagnosis
7. Treatment

8. Conclusion

\section{Introduction}

Considered as an endocrine organ, the skin can be also seen as a mirror for many tumoral and nontumoral diseases. Many skin conditions appear to be the result of hormonal disfunctions, both hormone excess and hormone deficiency/resistance, as well as growth factor pathological signaling (1).

Acanthosis nigricans (AN) is rather poorly defined as a dermatological disease by itself and more as a common dermatological manifestation of systemic disorders. It presents a collection of traits: dark-brown hyperpigmentation accompanied by a local thickening of the skin and a velvety texture. The usual distribution of the lesions is symmetrical, concerning areas of the body with skin folds: the neck, axillae, forehead, antecubital and popliteal fossae, groin and umbilicus. The neck is most frequently affected, especially in children. The distribution pattern of $\mathrm{AN}$ with high frequency on the neck and axillae can be caused by potentiator cofactors such as friction or perspiration (2). Mechanical factors have an important role in proliferation of skin keratinocytes, their influence being integrated by complex cellular signaling.

Other areas that may be involved are conjunctiva, lips, eyelids, flexor and extensor surface of elbows and knees, knuckles - dorsal face, external genitalia, areolae, inner face of thighs and anus. In some cases, especially when associated with malignancies, AN may interest the mucosa of the oral cavity, esophagus, nose or larynx (3-5).

The first case was described in 1889 by Paul Gerson Unna, in a patient presenting with 'widespread pigmentation and papillary hypertrophy', the term AN, proposed by Unna, being coined later (1891) in publications by Pollitzer and Janovsky (6). AN is a skin condition, either associated with benign endocrine disorders, mostly with obesity and insulin resistance, or appearing as a paraneoplastic sign in various malignancies $(7,8)$.

As a skin lesion, AN is usually asymptomatic. It typically occurs before the age of 40 , most frequently in Native Americans, followed by Africans, Hispanics, Caucasians and rarely in Asians. Hud et al demonstrated predominance of AN in black women when compared to white women (9). 


\section{Methods}

A literature review of AN was performed by searching the PubMed and MEDLINE databases for all related English published articles. The research of literature is focused on pathogenesis of $\mathrm{AN}$, in studies published in the last 5 years.

\section{Etiology}

Several causes have been described for AN, resulting in multiple classifications. Some clinicians consider two groups: benign and paraneoplastic (10), while others consider three groups: benign, malignant, and syndromic $(11,12)$. Another more complex and useful classification, proposed by Sinha and Schwartz, is based on etiological criteria (13). We propose the following classification, to better group and understand AN pathology (Table I).

\section{Metabolic disorders}

Obesity associated AN is the most frequent form, lesion severity being related with weight excess. Lesions are often slowly reversible after weight loss. It is more common in obese patients with insulin resistance (14-16).

Syndromic AN is a form associated with a syndrome, and two types have been described: type A (HAIR-AN) presents with hyperandrogenemia (HA), insulin resistance (IR) and AN; type B presents with diabetes mellitus and ovarian hyperandrogenemia.

\section{Genetic disorders}

Unilateral AN is a rare inherited autosomal dominant form, which can occur at any age, not related to endocrinopathy. Lesions are unilateral and appear especially in the periumbilical area, back and thighs $(17,18)$.

Familial AN is a rare autosomal dominant disease. The condition has a self-limited evolution, which commonly develops from early childhood and stabilizes or recedes after a continuous progress till puberty. However, it may appear at any age (19).

Benign genetic AN develops from birth or early childhood, as a rare autosomal dominant form.

Autoimmune disorders. Autoimmune AN is usually determined by anti-insulin receptor antibodies that appear in autoimmune diseases (e.g., systemic lupus erythematosus) (20-22). Cases of AN accompanied by autoimmune manifestations but not type B insulin resistance, which responded to systemic immunosuppressive therapy, have been reported $(21,22)$. It has been speculated that some unknown autoantibodies other than the insulin-receptor antibody might generate mucocutaneous lesions found in AN. Some patients with AN who are positive for antinuclear antibodies (ANA), antimicrosomal antibodies (AMA) or show increased immunoglobulin levels might associate with disordered immunoreactivity not fitting any clinically recognizable syndromes (23).

Paraneoplastic AN, also called malignant AN. Lesions are induced by an internal malignancy and are clinically indistinguishable from benign forms, although they are often associated with intense pruritis. They usually have a rapid onset, either preceding, accompanying, or following the diagnosis of internal
Table I. Proposed classification of AN.

\begin{tabular}{ll} 
AN group & \multicolumn{1}{c}{ AN form } \\
\hline $\begin{array}{l}\text { Metabolic } \\
\text { disorders }\end{array}$ & $\begin{array}{l}\text { Obesity associated AN } \\
\text { Syndromic: - Type A } \\
\text { - Type B }\end{array}$ \\
$\begin{array}{l}\text { Genetic } \\
\text { disorders }\end{array}$ & $\begin{array}{l}\text { Unilateral acanthosis nigricans } \\
\text { Familial acanthosis nigricans } \\
\text { Benign genetic acanthosis nigricans } \\
\text { Autoimmune AN }\end{array}$ \\
AN associated with a known \\
autoimmune disease \\
AN associated only with autoantibodies \\
AN associated with wide range \\
of neoplasia \\
Medication side effect AN \\
Iatrogenic AN
\end{tabular}

AN, acanthosis nigricans.

cancer. Paraneoplastic AN occurs in the course of adenocarcinomas of abdominal organs and genitourinary cancers. Lung cancer, thyroid cancer and lymphoma are rarely associated with AN. Lesion progression mirrors the development of the tumor: the efficient treatment leads to AN regression, whereas recrudescence may suggest recurrence of the malignancy (24).

Iatrogenic disorders. AN may appear as an adverse effect of several medications that promote hyperinsulinemia: nicotinic acid, niacin, glucocorticoids, stilbestrol, methyltestosterone, estrogen, combined oral contraceptive pill, pituitary extract and growth hormone therapy (25). Although skin lesions are reversible when discontinuing treatment, the decision should be made according to the severity of the disease for which the treatment was administered. Erickson et al observed in rare cases that, at the site of insulin injection, AN lesion can appear as side effect. However, it has been proved that, with the correct insulin type prescription and proper administration technique, the development of AN may be prevented $(26,27)$.

Idiopathic AN. Acral AN occurs in some healthy, dark-skinned individuals. It is limited to dorsal surfaces of the hands and feet and less to elbows, knees and knuckles (28-30). It may be caused by yet unknown genetic factors that will later classify it in the group of genetic disorders (31).

Mixed-type AN. Combines two or more of the forms presented above. Usually, paraneoplastic new lesions add to older ones of other etiology (2).

\section{Diagnosis}

The diagnosis of AN is clinical, the confirmation being provided by a skin biopsy. The histological pattern of the 
lesion is common in all forms of $\mathrm{AN}$, comprising hyperkeratosis, epidermal folding, proliferation of melanocytes in the basal layer of the epidermis, leukocyte infiltration. The hyperpigmentation seems to result rather from thickening and hyperkeratosis than from excess of melanin (32). In malignant AN the dominant feature is hyperkeratosis, due to proliferation of keratinocytes, while the hyperpigmentation is minimal (7).

\section{Pathological conditions and disorders associated with acanthosis nigricans}

AN is considered a pigmentary dermatological disorder, that may accompany multiple endocrine pathologies. It has been commonly associated with obesity, insulin-resistant diabetes, polycystic ovary disease, hirsutism, Cushing syndrome, Addison disease, hypothyroidism, acromegaly and gigantism. The association of AN with rare diseases such as pinealoma, Cushing pituitary basophilism, ovarian hyperthecosis, stromal luteoma, ovarian dermoid cysts, Prader-Willi syndrome, leprechaunism, lipoatrophic diabetes, pineal hyperplasia syndrome, and Alstrom syndrome has also been described (33-40).

Multiple factors can be incriminated in the development of AN. Insulin resistance stands out as the most frequent of them. Insulin resistance can be classified in three types: type A characterized by the reduced number and dysfunction of insulin receptors; type B presenting antibodies against insulin receptors; and type C caused by a post-receptor defect $(41,42)$.

Hyperinsulinemia is regularly correlated with $\mathrm{AN}$ and the treatment of associated endocrine disorders like hypothyroidism is not always followed by regression of either the hyperinsulinemia or the AN. Insulin resistance is a disorder characterized by an inappropriate response of target cells to normal levels of insulin, followed by adaptive hyperinsulinemia. The most common cause of insulin resistance is the adipose tissue excess, responsible for many metabolic effects: increased circulating amounts of free fatty acids that directly interfere with insulin signaling, diminished muscle glucose uptake, increased gluconeogenesis in liver and exaggerated triglyceride synthesis. The adipose tissue further stimulates progression of AN through various adipokines such as: leptin, adiponectin, tumor necrosis factor- $\alpha$ and interleukin- $6(43,44)$. When the excess insulin needed can no longer be secreted by pancreatic $\beta$-cells, type 2 diabetes mellitus occurs. Insulin resistance was demonstrated to be associated with $\mathrm{AN}$, the presence of the dermatological condition proving to be a valuable, accessible sign for the diagnosis of the glucidic metabolic disturbance (44).

AN associated with subclinical atherosclerosis is a form which is not well documented. Until now only one study has evaluated the prevalence of carotid atherosclerosis in Mexican patients with AN (45).

Although less frequent than the obesity and insulin resistance-associated forms, the 'malignant' AN is a particularly important type, as it is a sign of an underlying malignancy. It actually represents a paraneoplastic syndrome, in $\sim 17 \%$ of cases appearing prior to the tumor diagnosis (46) and occasioning extensive clinical and paraclinical investigations that lead to the diagnosis.

Compared to other types of $\mathrm{AN}$, the malignant form appears more abruptly, the lesions are more widespread or in non-typical areas, progress more rapidly, are frequently pruritic and are often extended to the mucosa, especially the oral cavity $(2,47)$.

It is most commonly associated with adenocarcinomas of abdominal organs (70-90\%), especially gastric adenocarcinoma (55-61\%), followed by adenocarcinoma of the pancreas, ovaries, kidneys, bladder, bronchi, thyroid, bile duct, breasts, esophagus, and endometrium (46,48-58). Rarely, malignant AN can coexist with nonepithelial tumors such as sarcomas, lymphomas, schwannomas, leukemia, malignant melanomas or malignant pinealomas (7,59-61).

A special case of $\mathrm{AN}$ is that accompanying insulinoma. Even though the mechanism is presumed to be hyperinsulinemia, only a minority of the cases of insulinomas present associated $\mathrm{AN}$ (62). There has been a report of 31 cases of insulinoma, out of which none associated AN (63). The recognition of $\mathrm{AN}$ is benefic for the correct diagnosis of insulinoma, especially in children and adolescents, as it often manifests by loss of consciousness or seizures due to the undocumented hypoglycemic episodes (64). The presence of AN leads to either the evaluation of the insulin level, revealing the hyperinsulinemia, or to the suspicion of a malignant tumor, followed by extensive imaging investigation that unravel the insulinoma.

\section{Pathophysiology}

The pathophysiology of AN seems to be connected with the proliferation of epidermal keratinocytes and the dermal fibroblasts under a multitude of factors that are not fully understood. Biochemical mechanisms involved in developing the lesions are extremely complicated, comprising multiple cytokines and signaling pathway crosstalk. Some of these processes have been discovered, but many are still to be unraveled.

In cases of benign $\mathrm{AN}$, insulin or an IGF have been suggested as promoters of enhanced epidermal cell propagation. Other mediators seem to be involved as well, including fibroblast growth factor (FGF) and tyrosine kinase receptors like the epidermal growth factor receptor (65-67).

Hyperinsulinemia acts in multiple ways to induce AN: direct effect and an indirect one. The direct effect is represented by insulin activation of IGF-1 receptor due to its high concentration. The indirect effect is more complex in nature: it indirectly increases the free IGF-1 in circulation, this being the active fraction.

Insulin has been shown to reach keratinocytes by crossing the dermoepidermal junction (21). When present in low concentrations, insulin is known to regulate carbohydrate, lipid and protein metabolisms; it binds to 'classic' insulin receptors, therefore mildly promoting cellular growth. The increased circulating levels of insulin activate IGF receptors on keratinocytes, particularly IGF-1 receptors, which have similar size and subunit structure with insulin receptors, but have 100-1,000fold greater affinity for IGF-1 than for insulin (68). The binding of insulin to these receptors promotes proliferation of both keratinocytes and fibroblasts, resulting in AN (17).

IGF-1 is found in circulation both free and in a complex with insulin-like growth binding proteins (IGFBPs). The IGFBPs carry IGF-1 to the tissue, increase its half-life and regulate the concentration of the free IGF-1 fraction that is respon- 
sible for its metabolic effect. Hyperinsulinemia decreases the circulating concentration of IGFBP-1 and IGFBP-2, that increase the free IGF-1 levels in tissues, thus promoting cell proliferation and AN manifestation (69). Furthermore, high concentrations of insulin may determine the displacement of IGF-1 from IGFBPs, thus increasing the fraction of free IGF-1 in plasma and determining cell growth and differentiation.

Hereditary cases of AN tend to present FGF defects. Newly discovered mutations of FGF receptor were described in Crouzon syndrome with AN, hypochondroplasia, and severe achondroplasia with developmental delay and AN $(66,70,71)$. Furthermore, it seems that palifermin, a recombinant ligand of the FGF receptor (used to treat mucositis determined by some chemotherapeutical agents) leads to florid, though reversible, iatrogenic AN (72).

In case of the paraneoplastic AN, the cancer cells in the tumor of origin and metastases are secreting cytokines that influence pathologically the fibroblasts and keratinocytes, leading to AN. From a histopathologic point of view, the proliferation of keratinocytes predominates, resulting in hyperkeratosis and papillary hyperplasia, but minimal hyperpigmentation. Histological aspects are common to other forms of AN, not discriminating the paraneoplastic type (46).

The appearance of paraneoplastic AN is considered to be the effect of signaling molecules secreted by the tumor. The tumoral cells produce a variety of molecules and growth factors with autocrine, paracrine and systemic effects. The most incriminated in AN progression is transforming growth factor- $\alpha$ (TGF- $\alpha$ ). When secreted in large quantities by the tumoral cells, TGF- $\alpha$ can bind to the epidermal growth factor (EGF) receptor due to structural similarities, promoting proliferation and differentiation of keratinocytes. Other tumor-secreted molecules are IGF-1, FGF and $\alpha$-melanocyte stimulating hormone ( $\alpha$-MSH), responsible for the melanocyte pigmentation and for further stimulating the growth of keratinocytes, thus explaining the hyperpigmentation and hyperplasia (2).

\section{Treatment}

AN is not a disease per se, but a sign of various causes and is not treatable on its own. The evolution of the skin condition depends of that of the underlying disease, so the treatment of the AN actually aims the causing disorder. Diminishing of hyperkeratosis has been described in some patients, following insulin resistance correction (by maintaining a low-calorie diet and sustained physical activity) or obesity control by weight loss $(69,73,74)$.

For esthetic reasons, dermatologists treat AN with variable success by prescribing topical keratolytics: retinoids and podophyllin. Other cosmetic treatments in use include laser procedures, chemical peels or dermabrasion.

For the insulin resistance control, metformin, etretinate and octreotide were used with some success. Giri et al reported complete resolution of $\mathrm{AN}$ after 2 years of metformin, despite persistence of insulin resistance (75).

Rosiglitazone is also useful in the treatment of AN caused by insulin resistance (76-78). Bellot-Rojas et al described lower fasting insulin levels with rosiglitazone as compared to metformin treatment, both variants leading to skin texture improvements of moderate magnitude (77). Metformin treat- ments that lead to insulin resistance and $\mathrm{AN}$ improvement are the ones with duration of more than 6 months. Metformin reduces peripheral insulin resistance, hyperinsulinemia, glucose production and body weight $(69,79)$. A good response of AN has been recorded after increasing sensitivity to insulin in peripheral muscles, by treatment with a combination of metformin and thiazolidindiones (80-82).

Melatonin treatment ( $3 \mathrm{mg} /$ day) has proved useful in improving both insulin resistance and pigmentation in obesityrelated $\mathrm{AN}$ (83).

The AN accompanying insulin resistance of autoimmune etiology, including antibodies against insulin receptor or against insulin itself, is treated with immunomodulatory regimens consisting of rituximab, dexamethasone and cyclophosphamide (20). For the autoimmune form not related to insulin resistance, moderate success in treating generalized $\mathrm{AN}$ has been reported for the use of cyclosporine A, with significant reduction of both the skin and mucosal papillomatous lesions (21).

The evolution of paraneoplastic AN is tightly connected to the evolution of cancer, regressing after the surgical ablation of the tumor or in some cytostatic treatments; it could even be a valuable parameter for monitoring of therapy, since it reactivates in case of tumor relapse or development of metastases (84).

In the particular case of $\mathrm{AN}$ associated with insulinoma, since the tumor is well circumscribed and surgically curable, the skin lesion may completely disappear when the removal of the insulinoma is achieved $(62,85)$. There has even been a report of complete remission of $\mathrm{AN}$ after the partial pancreatectomy for the HAIR-AN syndrome (86).

\section{Conclusion}

AN is a dermatological issue that is, in fact, an echo of a systemic disorder. The underlying disease can be a malignant or benign one, the latter ranging from mild metabolic disorders to diabetes mellitus or endocrine syndromes with important implication for the patients' health. Since some cases of AN precede or are discovered simultaneously with the causal malignant pathology, the clinician must thoroughly investigate the patient to be able to exclude the paraneoplastic form. The present review summarizes the etiopathogenesis and implications regarding different $\mathrm{AN}$ forms and proposes a new AN classification that might help with patient diagnosis, risk stratification and treatment protocol.

AN treatment represents in fact the treatment of the underlying condition, with a rich palette of approaches and a wide range of results. The local treatments applied for esthetic reason comprise several methods, with moderate results.

\section{Acknowledgements}

We reserve special thanks to Dr. Ovidiu Constantin Gheorghisan for his contribution in crystallizing the last form of the paper and to Ms. Irina Radu, certified translator in medicine and pharmacy (certificate credentials: series E, no. 0048), for professional linguistic assistance.

\section{Funding}

No funding was received. 


\section{Availability of data and materials}

All data were extracted from English-published papers, indexed in PubMed or MEDLINE databases.

\section{Authors' contributions}

MLP and AAGG were responsible for gathering all the necessary publications and drafting the work. ACP contributed to writing the manuscript, initiated the novel classification of AN and prepared the table. CT contributed to the conception of the review and the critical revision of the manuscript. All authors read and approved the final version of the manuscript.

\section{Ethics approval and consent to participate}

Not applicable.

\section{Patient consent for publication}

Not applicable.

\section{Competing interests}

The authors declare that they have no competing interests.

\section{References}

1. Quatrano NA and Loechner KJ: Dermatologic manifestations of endocrine disorders. Curr Opin Pediatr 24: 487-493, 2012.

2. Phiske MM: An approach to acanthosis nigricans. Indian Dermatol Online J 5: 239-249, 2014

3. Gómez-Flores M, González-Saldivar G, Santos-Santos O, Álvarez-Villalobos N, Rodríguez-Gutiérrez R, Tellez-Hinojosa C and González-González J: Implications of a clinically ignored site of acanthosis nigricans: The knuckles. Exp Clin Endocrinol Diabetes 123: 27-33, 2015.

4. Schnopp C and Baumstark J: Images in clinical medicine. Oral acanthosis nigricans. N Engl J Med 357: e10, 2007.

5. Judge MR, McLean WH and Munro C: Disorders of keratinization. In: Rook's Textbook of Dermatology. 8th edition. Burns T, Breathnach S, Cox N and Griffiths C (eds). Blackwell Publishing, Oxford, pp119-121, 2010.

6. Pollitzer S and Janovsky V: Acanthosis nigricans. In: International Atlas of Rare Skin Diseases. Vol. IV. Morris M, Unna PG, Leloir HC and Duhring L (eds). Leopold Voss, Hamburg, 1891.

7. Kutlubay Z, Engin B, Bairamov O and Tüzün Y: Acanthosis nigricans: A fold (intertriginous) dermatosis. Clin Dermatol 33: 466-470, 2015

8. Gossman WG and Bhimji SS: Acanthosis nigricans. In: StatPearls [Internet]. StatPearls Publishing, Treasure Island, FL, 2018

9. Hud JA Jr, Cohen JB, Wagner JM and Cruz PD Jr: Prevalence and significance of acanthosis nigricans in an adult obese population. Arch Dermatol 128: 941-944, 1992.

10. Hernández-Pérez E: On the classification of acanthosis nigricans. Int J Dermatol 23: 605-606, 1984.

11. Curth HO: Classification of acanthosis nigricans. Int $J$ Dermatol 15: 592-593, 1976.

12. Burke JP, Hale DE, Hazuda HP and Stern MP: A quantitative scale of acanthosis nigricans. Diabetes Care 22: 1655-1659, 1999.

13. Sinha S and Schwartz RA: Juvenile acanthosis nigricans. J Am Acad Dermatol 57: 502-508, 2007.

14. González-Saldivar G, Rodríguez-Gutiérrez R, OcampoCandiani J, González-González JG and Gómez-Flores M: Skin manifestations of insulin resistance: From a biochemical stance to a clinical diagnosis and management. Dermatol Ther (Heidelb) 7: 37-51, 2017.

15. Khokhar A, Chin V, Perez-Colon S, Farook T, Bansal S Kochummen E and Umpaichitra V: Differences between metabolically gealthy vs. unhealthy obese children and adolescents. J Natl Med Assoc 109: 203-210, 2017.
16. Panda S, Das A, Lahiri K, Chatterjee M, Padhi T, Rathi S, Dhar S and Sarma N: Facial acanthosis nigricans: A morphological marker of metabolic syndrome. Indian J Dermatol 62: 591-597, 2017.

17. Jeong KH, Oh SJ, Chon S and Lee MH: Generalized acanthosis nigricans related to type B insulin resistance syndrome: A case report. Cutis 86: 299-302, 2010.

18. Jeong JS, Lee JY and Yoon TY: Unilateral nevoid acanthosis nigricans with a submammary location. Ann Dermatol 23: 95-97, 2011.

19. Innaurato S, Brierley GV, Grasso V, Massimi A, Gaudino R, Sileno S, Bernardini S, Semple R and Barbetti F: Severe insulin resistance in disguise: A familial case of reactive hypoglycemia associated with a novel heterozygous INSR mutation. Pediatr Diabetes 19: 670-674, 2018.

20. Kim HN, Fesseha B, Anzaldi L, Tsao A, Galiatsatos P and Sidhaye A: Antibody-mediated extreme insulin resistance: A Report of three cases. Am J Med 131: 102-106, 2018.

21. Kondo Y, Umegaki N, Terao M, Murota H, Kimura T and Katayama I: A case of generalized acanthosis nigricans with positive lupus erythematosus-related autoantibodies and antimicrosomal antibody: Autoimmune acanthosis nigricans? Case Rep Dermatol 4: 85-91, 2012.

22. Miquel J, Hadj-Rabia S, Boddaert N, Lascelles K and Bahi-Buisson N: Atypical presentation of neuropsychiatric lupus with acanthosis nigricans. Pediatr Neurol 47: 291-294, 2012.

23. Sturner RA, Denning S and Marchase P: Acanthosis nigricans and autoimmune reactivity. JAMA 246: 763-765, 1981.

24. Schwartz RA: Acanthosis nigricans. J Am Acad Dermatol 31: $1-22,1994$

25. Hartman R, Defelice T, Tzu J, Meehan S and Sanchez M: Acanthosis nigricans in the setting of niacin therapy. Dermatol Online J 17: 11, 2011.

26. Erickson L, Lipschutz DE, Wrigley W and Kearse WO: A peculiar cutaneous reaction to repeated injections of insulin. JAMA 209: 934-935, 1969.

27. Sawatkar GU, Dogra S, Bhadada SK and Kanwar AJ: Acanthosis nigricans - an uncommon cutaneous adverse effect of a common medication: Report of two cases. Indian J Dermatol Venereol Leprol 79: 553, 2013.

28. Bishnoi A and Parsad D: Velvety hyperpigmentation on hands and feet of a young girl: Acral acanthosis nigricans. J Cutan Med Surg 22: 323, 2018.

29. Kura MM and Sanghavi SA: Acral acanthosis nigricans in a case of scleroderma. Indian J Dermatol 60: 423, 2015.

30. Anand V, Das A, Kumar P, Kumar R and Hassan S: Acral acanthosis nigricans (acral acanthotic anomaly). Indian Dermatol Online J 5 (Suppl 2): S140-S141, 2014.

31. Cama A, Sierra ML, Kadowaki T, Kadowaki H, Quon MJ, Rüdiger HW, Dreyer M and Taylor SI: Two mutant alleles of the insulin receptor gene in a family with a genetic form of insulin resistance: A 10 base pair deletion in exon 1 and a mutation substituting serine for asparagine-462. Hum Genet 95: 174-182, 1995.

32. Puri N: A study of pathogenesis of acanthosis nigricans and its clinical implications. Indian J Dermatol 56: 678-683, 2011.

33. Degirmentepe EN, Gungor S, Kocaturk E, Kiziltac U, Adas M, Ozekinci S and Khachemoune A: Dermatologic manifestations of acromegaly: A case in point and a focused review. Dermatol Online J 23: 23, 2017.

34. Yosipovitch G, DeVore A and Dawn A: Obesity and the skin: Skin physiology and skin manifestations of obesity. J Am Acad Dermatol 56: 901-916, quiz 917-920, 2007.

35. Jabbour SA: Cutaneous manifestations of endocrine disorders: A guide for dermatologists. Am J Clin Dermatol 4: 315-331, 2003.

36. Schmidt TH, Khanijow K, Cedars MI, Huddleston H, Pasch L, Wang ET, Lee J, Zane LT and Shinkai K: Cutaneous findings and systemic associations in women with polycystic ovary syndrome. JAMA Dermatol 152: 391-398, 2016.

37. Stratakis CA: Skin manifestations of Cushing's syndrome. Rev Endocr Metab Disord 17: 283-286, 2016.

38. Ober KP: Acanthosis nigricans and insulin resistance associated with hypothyroidism. Arch Dermatol 121: 229-231, 1985.

39. Scheinfeld NS: Obesity and dermatology. Clin Dermatol 22: 303-309, 2004

40. Gheorghisan-Galateanu AA, Terzea D, Valea A and Carsote M: Menopausal androgen excess - associated cardio-metabolic risk: Clues for ovarian Leydig cell tumour (case report and mini-review of literature). Acta Endocrinol (Copenh) 13: 356-363, 2017.

41. Moller DE and Flier JS: Insulin resistance - mechanisms, syndromes, and implications. N Engl J Med 325: 938-948, 1991. 
42. Barbato MT, Criado PR, Silva AK, Averbeck E, Guerine MB and Sá NB: Association of acanthosis nigricans and skin tags with insulin resistance. An Bras Dermatol 87: 97-104, 2012.

43. Assunção SN, Boa Sorte NC, Alves CA, Mendes PS, Alves CR and Silva LR: Glucose alteration and insulin resistance in asymptomatic obese children and adolescents. J Pediatr (Rio J) 94: 268-272, 2018

44. Rodríguez-Gutiérrez R, Salcido-Montenegro A and GonzálezGonzález JG: Early clinical expressions of insulin resistance: The real enemy to look for. Diabetes Ther 9: 435-438, 2018.

45. Guevara-Gutiérrez E, Tlacuilo-Parra A, Gutiérrez-Fajardo P, Sánchez-Tenorio T, Barba-Gómez F and Miranda-Díaz A: A study of the association of acanthosis nigricans with subclinical atherosclerosis. Indian J Dermatol Venereol Leprol 83: 190-194, 2017.

46. Krawczyk M, Mykała-Cieśla J and Kołodziej-Jaskuła A: Acanthosis nigricans as a paraneoplastic syndrome. Case reports and review of literature. Pol Arch Med Wewn 119: 180-183, 2009.

47. Ramirez-Amador V, Esquivel-Pedraza L, Caballero-Mendoza E, Berumen-Campos J, Orozco-Topete R and Angeles-Angeles A: Oral manifestations as a hallmark of malignant acanthosis nigricans. J Oral Pathol Med 28: 278-281, 1999.

48. Deen J, Moloney T and Burdon-Jones D: Severe, malignant acanthosis nigricans associated with adenocarcinoma of the endometrium in a young obese female. Case Rep Dermatol 9: 30-37, 2017.

49. Moreno-Artero E, Querol E, Ivars M, Sola I, Pío R and España A: Assessment of EGF receptor ligand expression in gastric carcinoma and in lesional skin of paraneoplastic acanthosis nigricans: A case report. J Eur Acad Dermatol Venereol 31: e301-e302, 2017.

50. Tammaro A, Giulianelli V, Parisella F and Persechino S: Bilaterally mammary acanthosis nigricans as paraneoplastic manifestation of prostate adenocarcinoma. G Ital Dermatol Venereol 151: 578-579, 2016

51. Karakas Y, Esin E, Lacin S, Ceyhan K, Heper AO and Yalcin S: A case of acanthosis nigricans as a paraneoplastic syndrome with squamous cell lung cancer. OncoTargets Ther 9: 4815-4820, 2016.

52. Ferraz de Campos FP, Narvaez MR, Reis PV, Gomes AC, Paraskevopoulos DK, Santana F and Fugita OE: Acanthosis nigricans associated with clear-cell renal cell carcinoma. Autops Case Rep 6: 33-40, 2016.

53. Vilas-Sueiro A, Suárez-Amor Ó, Monteagudo B and de Las Heras C: Malignant acanthosis nigricans, florid cutaneous and mucosal papillomatosis, and tripe palms in a man with gastric adenocarcinoma. Actas Dermosifiliogr 106: 438-439, 2015.

54. Ni QF, Liu GQ, Pu LY, Kong LL and Kong LB: Dermatomyositis associated with gallbladder carcinoma: A case report. World J Hepatol 5: 230-233, 2013.

55. Olek-Hrab K, Silny W, Zaba R, Osmola-Mańkowska A, Mackiewicz-Wysocka $M$ and Dańczak-Pazdrowska A: Co-occurrence of acanthosis nigricans and bladder adenocarcinoma - case report. Contemp Oncol (Pozn) 17: 327-330, 2013.

56. Solomon I, Voiculescu VM, Caruntu C, Lupu M, Popa A, Ilie MA, Albulescu R, Caruntu A, Tanase C, Constantin C et al: Neuroendocrine factors and head and neck squamous cell carcinoma: An affair to remember. Dis Markers 2018: 9787831 , 2018. doi: $10.1155 / 2018 / 9787831$

57. Voiculescu VM, Caruntu C, Solomon I, Lupu M, Ilie MA, Boda D, Constantin C and Neagu M: Squamous cell carcinoma - Biomarkers and potential therapeutic targets. In: Human Skin Cancers, Potential Biomarkers and Therapeutic Targets. Blumberg M (ed). IntechOpen, London, pp135-159, 2018.

58. Tanase CP, Neagu M and Albulescu R: Key signaling molecules in pituitary tumors. Expert Rev Mol Diagn 9: 859-877, 2009.

59. Moore RL and Devere TS: Epidermal manifestations of internal malignancy. Dermatol Clin 26: 17-29, 2008.

60. Mascitti M, Santarelli A, Albanese A, Campisi G and Muzio LL: Paraneoplastic acanthosis nigricans maligna. Ann Stomatol (Roma) 4 (Suppl 2): 29, 2013

61. Lupu M, Caruntu A, Caruntu C, Papagheorghe LM, Ilie MA, Voiculescu V, Boda D, Constantin C, Tanase C, Sifaki M, et al: Neuroendocrine factors: The missing link in non melanoma skin cancer (Review). Oncol Rep 38: 1327-1340, 2017.

62. Patra S, Chakraborty PP, Barman H and Santra G: Acanthosis nigricans in insulinoma: before and after successful surgical enucleation. BMJ Case Rep 2016: bcr2016218003, 2016. doi: 10.1136/bcr-2016-218003.

63. Jyotsna VP, Raizada N, Chakraborty S and Pal S: Acanthosis nigricans in insulinoma. Indian J Endocrinol Metab 18: 739, 2014

64. Gudala M, Ahmed M, Conroy R and Tonyushkina K: Insulinoma masquerading as a loss of consciousness in a teenage girl: Case report and literature review. Int J Pediatr Endocrinol 2017: 13, 2017.
65. Higgins SP, Freemark M and Prose NS: Acanthosis nigricans: A practical approach to evaluation and management. Dermatol Online J 14: 2, 2008.

66. Torley D, Bellus GA and Munro CS: Genes, growth factors and acanthosis nigricans. Br J Dermatol 147: 1096-1101, 2002

67. Neagu M, Caruntu C, Constantin C, Boda D, Zurac S, Spandidos DA and Tsatsakis AM: Chemically induced skin carcinogenesis: Updates in experimental models (Review). Oncol Rep 35: 2516-2528, 2016.

68. Rudman SM, Philpott MP, Thomas GA and Kealey T: The role of IGF-I in human skin and its appendages: Morphogen as well as mitogen? J Invest Dermatol 109: 770-777, 1997.

69. Napolitano M, Megna M and Monfrecola G: Insulin resistance and skin diseases. Sci World J 2015: 479354, 2015.

70. Blomberg M, Jeppesen EM, Skovby F and Benfeldt E: FGFR3 mutations and the skin: Report of a patient with a FGFR3 gene mutation, acanthosis nigricans, hypochondroplasia and hyperinsulinemia and review of the literature. Dermatology 220: 297-305, 2010

71. Mir A, Wu T and Orlow SJ: Cutaneous features of Crouzon syndrome with acanthosis nigricans. JAMA Dermatol 149: 737-741, 2013.

72. Lane SW, Manoharan S and Mollee PN: Palifermin-induced acanthosis nigricans. Intern Med J 37: 417-418, 2007.

73. Zhang Y, Zhu C, Wen X, Wang X, Li L, Rampersad S, Lu L, Zhou D, Qian C, Cui R, et al: Laparoscopic sleeve gastrectomy improves body composition and alleviates insulin resistance in obesity related acanthosis nigricans. Lipids Health Dis 16: 209, 2017.

74. Gheuca Solovastru L, Vata D, Statescu L, Constantin MM and Andrese E: Skin cancer between myth and reality, yet ethically constrained. Rev Rom Bioet 12: 47-52, 2014.

75. Giri D, Alsaffar H and Ramakrishnan R: Acanthosis nigricans and its response to metformin. Pediatr Dermatol 34: e281-e282, 2017.

76. Romo A and Benavides S: Treatment options in insulin resistance obesity-related acanthosis nigricans. Ann Pharmacother 42: 1090-1094, 2008.

77. Bellot-Rojas P, Posadas-Sanchez R, Caracas-Portilla N, Zamora-Gonzalez J, Cardoso-Saldaña G, Jurado-Santacruz F and Posadas-Romero C: Comparison of metformin versus rosiglitazone in patients with Acanthosis nigricans: A pilot study. J Drugs Dermatol 5: 884-889, 2006.

78. Sinha SK, Bhangoo A, Anhalt H, Maclaren N, Marshall JD, Collin GB, Naggert JK and Ten S: Effect of metformin and rosiglitazone in a prepubertal boy with Alström syndrome. J Pediatr Endocrinol Metab 20: 1045-1052, 2007.

79. Hermanns-Lê T, Scheen A and Piérard GE: Acanthosis nigricans associated with insulin resistance: Pathophysiology and management. Am J Clin Dermatol 5: 199-203, 2004.

80. Kumar N, Kaul CL, Ishrath A and Dey CS: Combination of metformin and thiazolidindiones restore insulin signalling in insulin-resistant cultured myotubes. Life Sci 74: 1877-1888, 2004.

81. Elkind-Hirsch KE: Thiazolidinediones for the therapeutic management of polycystic ovary syndrome: Impact on metabolic and reproductive abnormalities. Treat Endocrinol 5: 171-187, 2006.

82. Valizadeh N, Tehrani MR, Amoli MM and Bandarian F: Severe acanthosis nigricans in a 17 year-old female with partial lipodystrophic syndrome. J Pediatr Endocrinol Metab 21: 1027-1028, 2008

83. Sun H, Wang X, Chen J, Gusdon AM, Song K, Li L and Qu S: Melatonin treatment improves insulin resistance and pigmentation in obese patients with acanthosis nigricans. Int $\mathrm{J}$ Endocrinol 2018: 2304746, 2018.

84. Gorisek B, Krajnc I, Rems D and Kuhelj J: Malignant acanthosis nigricans and tripe palms in a patient with endometrial adenocarcinoma - a case report and review of literature. Gynecol Oncol 65: 539-542, 1997.

85. Ghosh S, Roychowdhury B, Mukhopadhyay S and Chowdhury S: Clearance of acanthosis nigricans associated with insulinoma following surgical resection. QJM 101: 899-900, 2008.

86. Pfeifer SL, Wilson RM and Gawkrodger DJ: Clearance of acanthosis nigricans associated with the HAIR-AN syndrome after partial pancreatectomy: An 11-year follow-up. Postgrad Med J 75: 421-422, 1999.

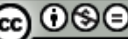

This work is licensed under a Creative Commons Attribution-NonCommercial-NoDerivatives 4.0 International (CC BY-NC-ND 4.0) License. 